\title{
Sistem Monitoring Parkir Mobil menggunakan Sensor Infrared berbasis RASPBERRY PI
}

\author{
DECY NATALI ANA ${ }^{1}$, I QBAL SYAMSU ${ }^{2}$, GALI H GI ANTARA ${ }^{1}$ \\ 1. Teknik Elektro Institut Teknologi Nasional Bandung \\ 2. Lembaga IImu Pengetahuan Indonesia (LIPI) \\ Email : decy@itenas.com
}

\begin{abstract}
ABSTRAK
Masalah yang selalu timbul dalam sistem perparkiran adalah kurangnya informasi mengenai status ketersediaan lahan parkir, untuk itu diperlukan sebuah sistem monitoring parkir. Tujuan penelitian ini adalah merancang dan merealisasikan model sistem monitoring perparkiran dengan fasilitas pemilihan area parkir dengan berbasiskan Raspberry Pi serta pemanfaatan infrared sebagai sensor. Sistem ini mampu menampilkan status ketersediaan dari area parkir yang ditampilkan pada display serta dilengkapi dengan perhitungan tarif parkir. Pada sistem yang dirancang dilengkapi dengan tombol untuk memilih area parkir, 2 buah sensor pada masing-masing area parkir untuk mendeteksi kendaraan, kamera untuk kemanan dan lampu LED sebagai indikator ketersediaan area parkir. Perangkat lunak yang digunakan pada sistem ini dirancang dengan menggunakan bahasa Python 2 dan untuk sistem database digunakan SQLite3. Pengujian dilakukan secara simulasi pada miniatur perparkiran. Hasil pengujian model sistem perparkiran dapat menampilkan kondisi dari masing-masing area parkir yang ditampilkan pada display. Kedua buah LED berhasil menjadi indikator ada tidaknya lahan parkir yang masih kosong. Untuk sistem perhitungan tarif parkir telah sesuai dengan perhitungan lamanya parkir.
\end{abstract}

Kata kunci : Parkir, Raspberry Pi , Infrared, Python 2, Monitoring.

\begin{abstract}
The problem which always happens in parking system is the lack of information about the parking area. That's why we need parking monitoring system. The purposes of this project are to devise and create parking monitoring system which has fitur for ordering parking area. The system based on Raspberry Pi. The system use infra red as sensor. Beside show the availability status of parking area in a display, this system also calculates the price of using the parking area. The System equipped with button for ordering parking area, 2 infrared sensors for each area, web camera for security and 2 LED lamps for availability indicator. Software for this system is made by Pyhton 2 language. For database the system use SQLite 3 as database system. The trial for this system done with simulation in a miniatur parking area. The result of the trial is the system can display about status of parking area. The system is also can make red LED and green LED light depend on the status of parking area. For billing system, the calculation of parking rates fits with the calculation of parking duration.
\end{abstract}

Keywords : Parking, Raspberry Pi, Infra Red, Python 2, Monitoring. 


\section{PENDAHULUAN}

Seiring perkembangan jaman, penggunaan mobil pribadi sebagai alat transportasi sudah menjadi hal yang umum. Hal ini berdampak pada makin banyaknya lahan-lahan parkir yang disediakan oleh tempat-tempat umum. Akan tetapi hal ini tidak dibarengi dengan peningkatan kualitas dan kenyamanan tempat parkir tersebut.

Para pengguna mobil pribadi yang hendak parkir kurang mendapat informasi mengenai keadaan area parkir seperti masih ada atau tidaknya lahan parkir yang kosong serta lokasi area parkir yang kosong. Akibat dari kurangnya informasi yang didapat, seringkali para pengguna mobil perlu memakan waktu yang lama untuk sekedar menemukan tempat yang kosong. bahkan tidak jarang pada akhirnya pengguna tersebut tidak mendapat tempat parkir sama sekali.

Pada penelitian yang dilakukan oleh Achdian (Asfin Achdian, 2012) berjudul "Rancang Bangun Alat Monitoring Parkir Nirkabel berbasis Mikrontroler ATMEGA8535", menjelaskan bahwa pada penelitiannya digunakan LCD $2 \times 16$ pada sistem untuk menampilkan informasi mengenai lahan parkir serta menghitung banyaknya area yang kosong dan belum terisi pada suatu tempat parkir yang kemudian akan ditampilkan pada 7 segment. Hasil uji coba menunjukkan alat yang dirancang sudah dapat memberikan hasil yang baik dalam sistem perparkiran khususnya roda empat.

Pada penelitian yang dilakukan oleh Asep (Asep Irfan Helmi, 2006) berjudul "Perancangan dan Realisasi Model Sistem Perparkiran dengan Pemilihan Lantai Parkir berbasis Mikrokontroler dan PC pada gedung bertingkat", menjelaskan bahwa sistem dapat memberikan informasi perparkiran yang kemudian akan ditampilkan pada display monitor. Informasi yang ditampilkan antara lain kondisi area parkir apakah terisi oleh kendaraan atau tidak, durasi dari lamanya parkir, serta biaya yang harus dibayarkan oleh pengguna lahan parkir.

berdasarkan penelitian-penelitian tersebut, maka akan diimplementasikan sebuah sistem monitoring parkir mobil dengan menggunakan sensor infrared berbasiskan Raspberry Pi. Penelitian ini bertujuan untuk merancang dan merealisasikan sistem monitoring parkir yang dapat memberitahukan ketersediaan area parkir kepada pengguna kendaraan serta mampu menghitung tarif dari penggunaan area parkir dengan memanfaatkan Raspberry Pi sebagai basis sistem serta infrared sebagai sensor. Dengan sistem tersebut, diharapkan permasalahan akan kurangnya informasi yang didapat oleh pengendara mobil mengenai ketersediaan lahan parkir serta lokasi tempat parkir yang masih kosong dapat teratasi sehingga dapat memberikan kenyamanan bagi para pengendara mobil yang hendak parkir.

Ada beberapa kelebihan dari penggunaan Raspberry Pi untuk sistem yang dirancang. Selain karena konsumsi dayanya yang lebih kecil dari sebuah personal computer, terdapat pin-pin GPIO yang dapat difungsikan sebagai input atau output yang dapat langsung dihubungkan dengan sensor atau komponen-komponen elektronika lainnya yang akan digunakan dalam sistem sehingga lebih mudah dalam hal perancangan perangkat lunak untuk sistem.

Sistem yang dirancang dipalikasikan pada miniatur perparkiran mobil 2 lantai dengan ukuran panjang $50 \mathrm{~cm}$, lebar $30 \mathrm{~cm}$ dan tinggi $20 \mathrm{~cm}$ untuk lantai 1 serta $15 \mathrm{~cm}$ untuk lantai 2 . Masing-masing lantai memiliki 2 area parkir dengan masing-masing area parkir memiliki 2 buah sensor infrared dan dipasang dengan ketinggian $4 \mathrm{~cm}$ dan jarak antara pemancar dan penerima infrared adalah sejauh $15 \mathrm{~cm}$. Raspberry Pi yang di gunakan pada sistem adalah Raspberry Pi tipe B dengan sistem operasi Raspbian dan menggunakan bahasa pemrograman Python 2.x. Kondisi traffic pada sistem dianggap ideal. 


\section{METODOLOGI}

Sistem yang dirancang bersifat model sistem. Pada perancangan sistem terdiri dari 2 bagian yaitu perancangan perangkat keras dan perancangan perangkat lunak. Perancangan dan realisasi alat yang dibuat menghasilkan model sistem dengan batasan sebagai berikut:

1. Sistem yang dirancang adalah sistem untuk area parkir 2 lantai dengan masing-masing lantai memiliki 2 area blok parkir.

2. Sensor infrared diletakkan di samping area blok parkir. 2 buah pasang sensor untuk masing-masing blok parkir.

3. Sensor ini hanya mendeteksi ada tidaknya kendaraan pada area blok parkir.

4. Raspberry Pi yang digunakan adalah Raspberry Pi tipe-B

Raspberry Pi merupakan komputer mungil seukuran dengan sebuah kartu kredit dengan berbagai fungsi yang dapat dilakukannya. Raspberry Pi menggunakan sistem operasi Raspbian. Raspberry memiliki prosesor yang memiliki spesifikasi 700MHz ARM11. Ada 2 tipe dari Raspberry Pi yakni tipe A dan B. Pada Tipe B RAM yang dimiliki adalah sebesar 512 MB. Raspberry Pi menggunakan SD Card sebagai media penyimpanannya. Selain itu Raspberry juga dilengkapi 2 buah port USB untuk tipe B, konektor HDMI, lalu untuk tipe B, Raspberry Pi dilengkapi dengan port ethernet. Pada Raspberry Pi tidak disediakan switch power. Port micro USB pada Raspberry Pi digunakan sebagai supply power, penggunaan micro USB dikarenakan murah dan mudah didapatkan. Raspberry Pi membutuhkan supply sebesar 5V dengan arus minimal $700 \mathrm{~mA}$ untuk tipe $B$ dan $500 \mathrm{~mA}$ untuk tipe $A$ (Richardson and Wallace, 2012).

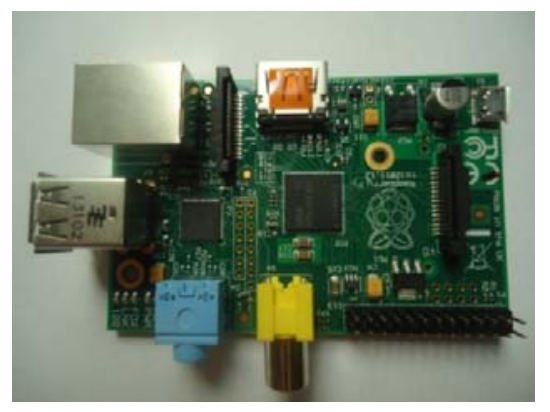

Gambar 1. Raspberry Pi

Pada Raspberry Pi disediakan pin-pin input/output (IO), diantaranya adalah:

1. General Purpose Input dan Output (GPIO)

Pin-pin tersebut dapat digunakan untuk membaca input dari tombol serta switches serta mengontrol aktuator seperti LED, relay dan motorifungsikan sebagai input atau output data digital.

2. The Display Serial Interface (DSI) connector

Konektor ini dapat digunakan dengan menggunakan kabel pita tipis 15 pin sebagai penghubung antara LCD atau layar OLED

3. The Camera Serial Interface (CSI) connector

Port ini berfungsi sebagai penghubung langsung antara Raspberry Pi dengan sebuah modul kamera (Richardson and Wallace, 2012).

\subsection{Perancangan Perangkat Keras}

Blok diagram dari perangkat keras pada model sistem monitoring parkir menggunakan sensor infrared berbasiskan Raspberry Piseperti yang terlihat pada Gambar 2. 


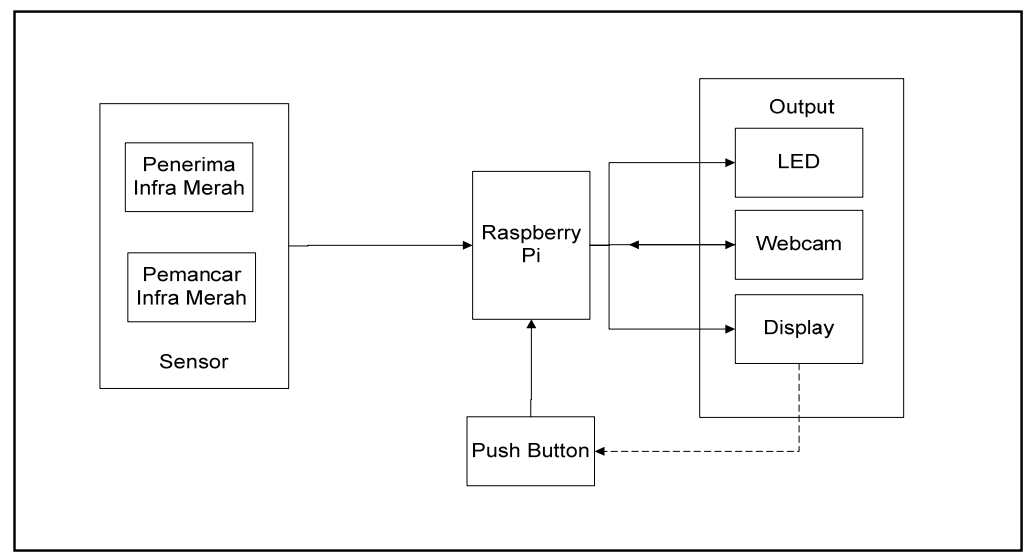

Gambar 2. Blok Diagram Perangkat Keras

Gambar 3 menjelaskan secara flowchart prinsip kerja sistem yang dirancang untuk sistem monitoring parkir menggunakan sensor infrared berbasiskan Raspberry Pi.

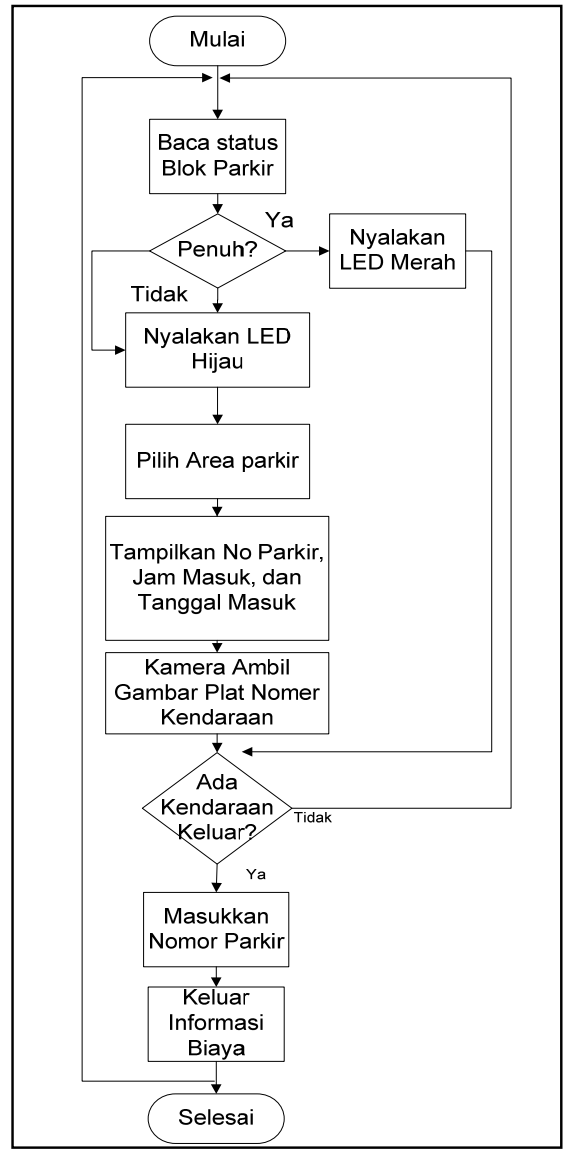

\section{Gambar 3. Diagram Alir Kerja Sistem Parkir}

Adapun prinsip kerja dari sistem parkir yang dirancang adalah pengguna kendaraan memesan area parkir yang masih kosong dengan melihat kondisi area parkir pada layar LCD. Status area parkir ditunjukkan dengan warna, putih menunjukkan area masih kosong, kuning untuk menunjukkan area sudah dipilih oleh pengguna kendaraan yang lain, dan merah menunjukkan area parkir telah terisi. Pengguna kendaraan memesan dengan menekan 
tombol pada papan tombol sesuai dengan area parkir yang diinginkan. Sesaat setelah pengguna menekan tombol area parkir yang diinginkan, pada layar LCD area parkir yang dipilih pengguna tadi akan berubah warnanya menjadi kuning. Saat menekan tombol kamera yang berada di pintu masuk area parkir akan menangkap gambar plat nomor kendaraan. Kemudian pengguna kendaraan mendapat informasi tentang nomor parkir yang ia dapatkan. Setelah pengguna kendaraan memarkirkan kendaraan di area yang telah dipilih, kendaraan akan menghalangi sensor dan warna area pada layar LCD menjadi berwarna merah. Ketika kendaraan selesai menggunakan area parkir, dan keluar dari area parkir, sensor menjadi tidak terhalang oleh kendaraan kembali dan warna area pada layar LCD menjadi putih.

Saat pengguna kendaraan menuju pintu keluar, pengguna kendaran akan memberikan informasi tentang nomor parkirnya tadi. Kemudian operator akan memasukkan nomor parkir ke dalam program, yang kemudian akan memberikan informasi jam masuk kendaraan, tanggal masuk kendaraan, lamanya kendaraan terparkir dan biaya parkir lampu LED berwarna merah akan menyala saat tidak ada lagi tempat parkir yang tersedia. Lampu LED berwarna hijau akan menyala saat masih ada area parkir yang tersedia.

Perancangan perangkat keras sistem monitoring parkir dibangun dengan mengintegrasikan beberapa subsistem dengan spesifikasi yang dapat dilihat pada Tabel 1.

Tabel 1. Spesifikasi Perangkat Keras

\begin{tabular}{|c|c|c|c|c|}
\hline No & Jenis & Tipe & Fungsi & Keterangan \\
\hline 1 & Raspberry Pi & B & Pengendali Sistem & 1 buah \\
\hline 2 & Sensor & $\begin{array}{l}\text { Led Infrared dan komponen } \\
\text { TSOP1133 }\end{array}$ & $\begin{array}{l}\text { Input: Mendeteksi ada tidaknya } \\
\text { kendaraan di tempat parkir }\end{array}$ & $\begin{array}{l}8 \text { pasang untuk } 4 \\
\text { blok area parkir }\end{array}$ \\
\hline 3 & $\begin{array}{l}\text { Tombol Pilih blok } \\
\text { area parkir }\end{array}$ & Switch push-on & Input: memilih area blok parkir & 4 buah \\
\hline 4 & $\begin{array}{l}\text { Indikator Tempat } \\
\text { Parkir Penuh }\end{array}$ & Lampu LED & $\begin{array}{l}\text { Output: sebagai penampil Penuh } \\
\text { Tidaknya Tempat Parkir }\end{array}$ & 2 buah \\
\hline 5 & Monitor & LCD & $\begin{array}{l}\text { Output: sebagai penampil } \\
\text { informasi Parkir }\end{array}$ & 1 buah \\
\hline 6 & Kamera & $\begin{array}{c}\text { Kamera web tipe: Logitech C110 } \\
\text { denga resolusi kamera 1.3 MP }\end{array}$ & $\begin{array}{c}\text { Mengambil gambar plat nomor } \\
\text { kendaraan }\end{array}$ & 1 buah \\
\hline
\end{tabular}

1. Papan Tombol

Pada papan tombol terdapat 4 buah tombol tekan (push-on) dimana setiap tombol digunakan untuk memilih atau memesan area parkir. Ujung setiap tombol dihubungkan ke ground dan ujung lain dihubungkan ke port GPIO pada Raspberry Pi dan tegangan sebesar 3.3 Volt. Gambar 4 memperlihatkan bentuk dari papan tombol dan rangkaian dari papan tombol yang dirancang.
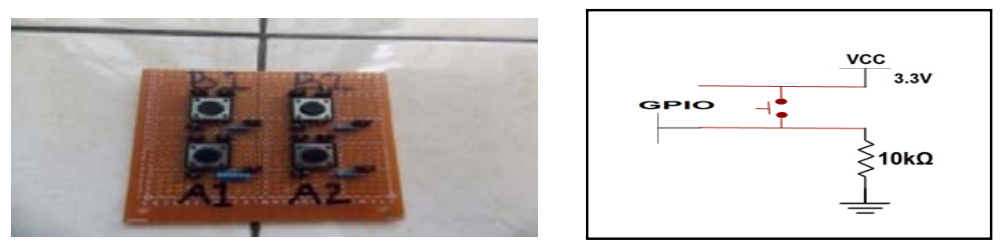

Gambar 4. Papan Tombol

Seperti terlihat pada Gambar 1 terdapat 4 buah tombol, yang masing masing terhubung dengan port GPIO pada Raspberry Pi. Port yang digunakan untuk masing-masing tombol dapat dilihat pada Tabel 2. 
Tabel 2. Port Tombol Pilihan

\begin{tabular}{|l|l|l|l|}
\hline No & Tombol & $\begin{array}{l}\text { Port } \\
\text { (Board) }\end{array}$ & $\begin{array}{l}\text { GPIO } \\
\text { (BCM) }\end{array}$ \\
\hline 1 & A1 & 11 & GPIO 17 \\
\hline 2 & A2 & 12 & GPIO 18 \\
\hline 3 & B1 & 13 & GPIO 27 \\
\hline 4 & B2 & 15 & GPIO 22 \\
\hline
\end{tabular}

2. Sensor Infrared

Unit Sensor Infrared berfungsi untuk mendeteksi ada tidaknya kendaraan pada area blok parkir. Unit ini menggunakan sebuah LED infrared pada bagian pemancar dan komponen TSOP 1133 pada bagian penerima. Gambar 5 merupakan gambar rangkaian pemancar sensor infrared dan gambar perangkat keras pemancar infrared yang telah dirancang.


Gambar 5. Pemancar infrared

Untuk komponen TSOP 1133 yang berfungsi sebagai penerima cahaya infrared memiliki 3 kaki seperti yang terlihat pada Gambar 6 .

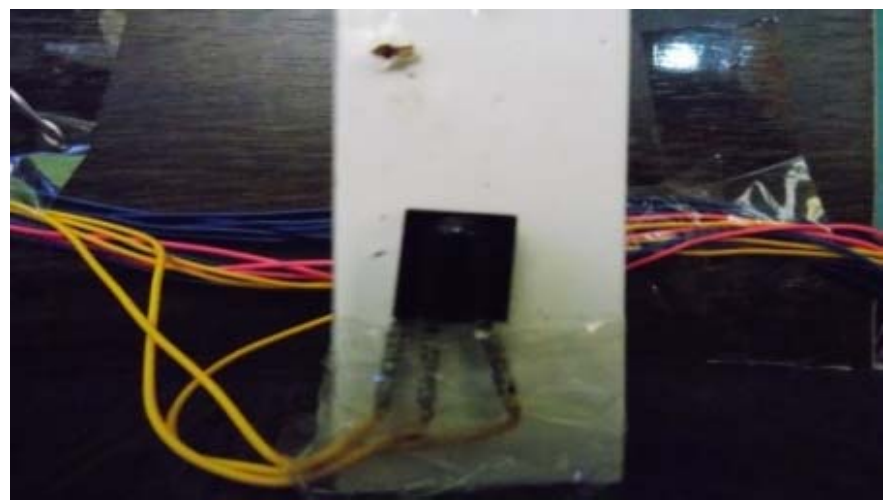

Gambar 6. Komponen Penerima Infrared

Kaki 1 dihubungkan dengan Ground, kaki 2 dihubungkan dengan sumber tegangan dari Raspberry Pi yaitu 3.3 Volt, dan kaki 3 dihubungkan pada GPIO pada Raspberry Pi. Port yang digunakan untuk masing-masing pemancar dapat dilihat pada Tabel 3. 
Tabel 3.2 Port Sensor Penerima Infrared

\begin{tabular}{|c|c|c|c|}
\hline No & Sensor & Port (Board) & GPIO(BCM) \\
\hline 1 & 1 pada A1 & 26 & GPIO 7 \\
\hline 2 & 2 pada A1 & 24 & GPIO 8 \\
\hline 3 & 1 pada A2 & 21 & GPIO 9 \\
\hline 4 & 2 pada A2 & 23 & GPIO 11 \\
\hline 5 & 1 pada B1 & 19 & GPIO 10 \\
\hline 6 & 2 pada B1 & 10 & GPIO 15 \\
\hline 7 & 1 pada B2 & 8 & GPIO 14 \\
\hline 8 & 2 pada B2 & 16 & GPIO 23 \\
\hline
\end{tabular}

\section{Rangkaian Lampu LED}

2 buah Lampu LED, 1 berwarna merah dan 1 berwarna hijau yang menunjukkan apakah area parkir telah penuh terisi atau masih ada area parkir yang masih kosong. Gambar 7 menunjukkan rangkaian yang digunakan pada indikator LED.

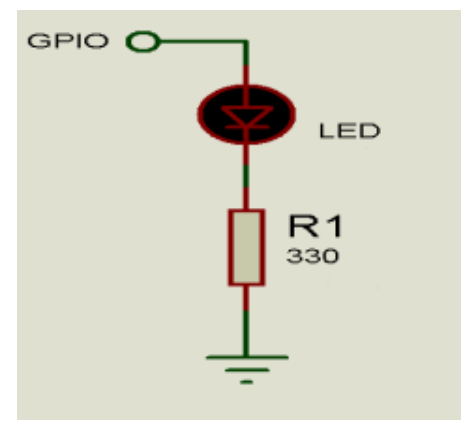

\section{Gambar 7. Rangkaian I ndikator Penuh Tempat Parkir}

\subsection{Perancangan Perangkat Lunak}

Perangkat lunak yang ada pada sistem Raspberry Pi mengggunakan bahasa Python 2. Bahasa Python merupakan bahasa pemrograman yang dikategorikan highlevel language. Berbeda dengan lowlevel language, Highlevel language tidak dapat langsung dijalankan oleh mesin, perlu diproses terlebih dahulu agar dapat dijalankan oleh mesin (Downey, 2012). Pada sisi interface, digunakan modul Tkinter yang merupakan interface standar yang biasa digunakan pada pemrograman Python (Lundh, 1999). Perangkat lunak yang dirancang memberikan instruksi kepada unit pemrosesan untuk membaca input dari sensor, tombol pilih lantai dan mengeluarkan data pada output untuk menyalakan indikator LED, memberikan perintah pada kamera untuk mengambil gambar. Sistem perparkiran yang dirancangang dilengkapi dengan sistem database. Pada sisi database digunakan SQLite. SQLite merupakan sebuah sistem manajemen basisdata relasional yang dirancang untuk mengelola data pada sebuah aplikasi dengan cara yang nyaman dan tanpa biaya yang mahal. Kelebihan dari SQLite adalah mudah digunakan, efisien dan dapat diandalkan (Owens, 2006). Pada perancangan, digunakan kamera web sebagai fitur untuk keamanan. Agar dapat terintegrasi dengan Python maka digunakan framework SimpleCV. SimpleCV merupakan kerangka Python yang berisikan libraries dan algortima untuk sistem computer vision (Oostendorp, Oliver and Scott, 2012). Sebuah Gambar 8 memperlihatkan diagram alir dari perangkat lunak untuk sistem parkir. 


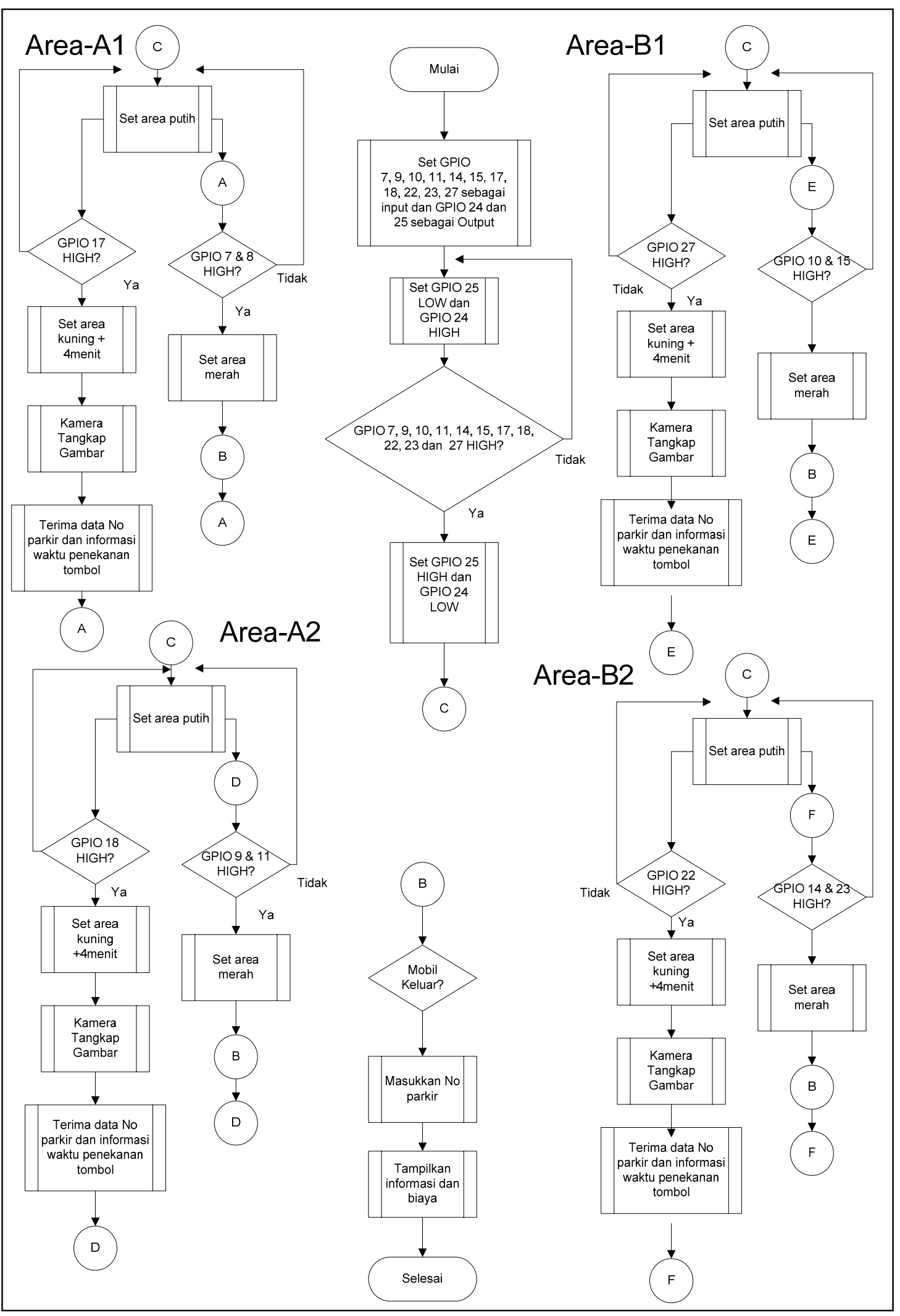

Gambar 8. Diagram Alir Perangkat Lunak Sistem Parkir 


\section{REALI SASI DAN PENGUJ I AN}

Realisasi dari alat yang dirancang untuk aplikasi sistem monitoring parkir menggunakan sensor infrared berbasiskan Raspberry Pi dapat dilihat pada Gambar 9.

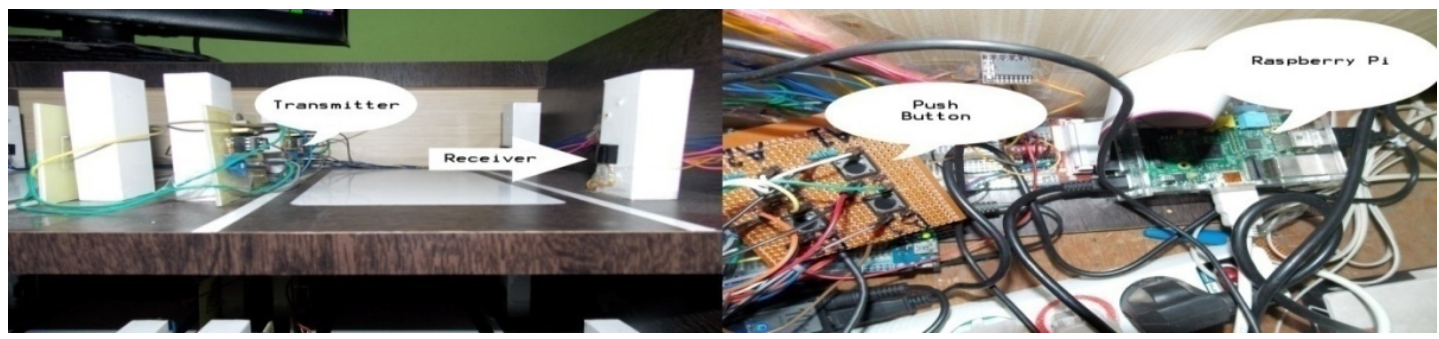

(a)

(b)

Gambar 9. Tampilan Fisik Alat yang Dirancang (a) bagian depan (b) bagian samping

\subsection{Pengujian Sensor Parkir}

Tujuan dari pengujian rangkaian sensor parkir ini adalah untuk mengetahui rangkaian ini dapat bekerja atau tidak serta mengetahui perubahan tegangan pada saat kondisi sensor terhalang dan tidak terhalang.

Tabel 4. Output Sensor Dalam Keadaan Terhalang

\begin{tabular}{|c|r|r|r|r|r|r|r|r|}
\hline \multirow{3}{*}{ Percobaan Ke } & \multicolumn{9}{|c|}{ Sensor Terhalang (Volt) } & \multicolumn{2}{|c|}{ B2 } \\
\cline { 2 - 9 } & \multicolumn{2}{|c|}{ A1 } & \multicolumn{2}{|c|}{ A2 } & \multicolumn{2}{c|}{ B1 } & \multicolumn{2}{c|}{ Sensor 2 } \\
\cline { 2 - 9 } & Sensor 1 & Sensor 2 & Sensor 1 & Sensor 2 & Sensor 1 & Sensor 2 & Sensor 1 & Sen \\
\hline 1 & 0.21 & 0.01 & 0 & 0 & 0 & 0.01 & 0.01 & 0 \\
\hline 2 & 0.14 & 0.01 & 0 & 0.1 & 0.1 & 0.01 & 0.01 & 0 \\
\hline 3 & 0.14 & 0 & 0 & 0 & 0 & 0 & 0 & 0.01 \\
\hline 4 & 0.1 & 0.01 & 0.01 & 0.01 & 0.01 & 0.01 & 0.01 & 0.01 \\
\hline 5 & 0.29 & 0 & 0.01 & 0 & 0 & 0 & 0.01 & 0.01 \\
\hline 6 & 0.28 & 0 & 0.01 & 0 & 0 & 0.01 & 0.01 & 0.01 \\
\hline 7 & 0.39 & 0 & 0.01 & 0 & 0 & 0.01 & 0 & 0.01 \\
\hline 8 & 0.24 & 0 & 0.01 & 0.01 & 0.01 & 0.01 & 0 & 0.01 \\
\hline 9 & 0.13 & 0 & 0.01 & 0.01 & 0.01 & 0.01 & 0 & 0 \\
\hline 10 & 0.31 & 0 & 0.01 & 0 & 0 & 0.01 & 0.01 & 0 \\
\hline
\end{tabular}

Tabel 5. Output Sensor Dalam Keadaan Tidak Terhalang

\begin{tabular}{|c|l|l|l|l|l|l|l|l|}
\hline \multirow{2}{*}{ Percobaan Ke } & \multicolumn{9}{|c|}{ Tidak Terhalang (Volt) } \\
\cline { 2 - 9 } & \multicolumn{2}{|c|}{ A1 } & \multicolumn{2}{c|}{ A2 } & \multicolumn{2}{c|}{ B1 } & \multicolumn{2}{c|}{ B2 } \\
\cline { 2 - 9 } & Sensor 1 & Sensor 2 & Sensor 1 & Sensor 2 & Sensor 1 & Sensor 2 & Sensor 1 & Sensor 2 \\
\hline 1 & 3 & 3 & 3 & 3 & 2.99 & 2.99 & 3 & 2.99 \\
\hline 2 & 3 & 3 & 3 & 2.98 & 2.99 & 3 & 2.99 & 3 \\
\hline 3 & 3 & 2.99 & 3 & 2.99 & 2.99 & 2.99 & 2.99 & 3 \\
\hline 4 & 3 & 2.99 & 3 & 2.99 & 2.99 & 2.99 & 3 & 2.99 \\
\hline 5 & 3 & 3 & 3 & 2.99 & 2.99 & 2.99 & 2.99 & 3 \\
\hline 6 & 3 & 3 & 2.99 & 2.99 & 3 & 2.99 & 2.99 & 2.98 \\
\hline 7 & 3 & 3 & 2.98 & 2.99 & 3 & 2.98 & 2.98 & 3 \\
\hline 8 & 3 & 3 & 3 & 2.99 & 3 & 3 & 3 & 2.99 \\
\hline 9 & 3 & 2.98 & 3 & 2.99 & 2.99 & 2.99 & 2.99 & 3 \\
\hline 10 & 3 & 2.99 & 3 & 2.98 & 2.98 & 2.99 & 2.99 & 2.99 \\
\hline
\end{tabular}


Dari hasil pengukuran didapat variasi tegangan saat sensor dalam keadaan terhalang dan dalam keadaan tidak terhalang. Dari Tabel 4 dan 5 didapat tegangan terbesar ada pada sensor 1 dari A1, yaitu sebesar 0.29 Volt, artinya, tegangan sebesar 0.29 Volt. Sensor dalam keadaan terhalang menunjukkan sensor akan memberikan inputan Low Voltage pada Raspberry Pi, sedangkan saat tidak terhalang akan memberi inputan High Voltage.

\subsection{Pengujian Rangkaian Push Button}

Tujuan dari pengujian rangkaian Push Button ini adalah untuk mengetahui rangkaian ini dapat bekerja atau tidak, dan mengetahui perubahan tegangan pada saat kondisi ditekan dan tidak ditekan.

\section{Tabel 6. Hasil Pengukuran Output Push Button}

\begin{tabular}{|r|l|l|l|l|r|r|r|r|r|}
\hline \multirow{2}{*}{ Percobaan Ke } & \multicolumn{7}{|c|}{ Push Button } \\
\cline { 2 - 10 } & \multicolumn{1}{|c|}{ Keadaan Ditekan } & \multicolumn{1}{|c|}{ (Volt) } & \multicolumn{4}{|c|}{ Tidak Ditekan (Volt) } \\
\cline { 2 - 10 } & A1 & A2 & B1 & B2 & A1 & A2 & B1 & B2 \\
\hline 1 & 3.26 & 3.25 & 3.26 & 3.26 & 0 & 0 & 0 & 0 \\
\hline 2 & 3.26 & 3.26 & 3.25 & 3.26 & 0 & 0 & 0 & 0 \\
\hline 3 & 3.25 & 3.26 & 3.26 & 3.25 & 0 & 0 & 0 & 0 \\
\hline 4 & 3.26 & 3.27 & 3.26 & 3.25 & 0 & 0 & 0 & 0 \\
\hline 5 & 3.26 & 3.26 & 3.26 & 3.25 & 0 & 0 & 0 & 0 \\
\hline 6 & 3.26 & 3.25 & 3.26 & 3.25 & 0 & 0 & 0 & 0 \\
\hline 7 & 3.26 & 3.26 & 3.26 & 3.26 & 0 & 0 & 0 & 0 \\
\hline 8 & 3.26 & 3.26 & 3.25 & 3.25 & 0 & 0 & 0 & 0 \\
\hline 9 & 3.26 & 3.25 & 3.25 & 3.25 & 0 & 0 & 0 & 0 \\
\hline 10 & 3.26 & 3.26 & 3.26 & 3.26 & 0 & 0 & 0 & 0 \\
\hline
\end{tabular}

Pada saat push button tidak ditekan, tegangan yang terukur pada voltmeter adalah sebesar 0 Volt sedangkan saat push button ditekan tegangan yang terukur pada volt meter berkisar antara 3.25-3.26 Volt. Ini berarti saat push button ditekan kondisi dari push button adalah High sedangkan pada saat tidak ditekan kondisi push button adalah Low.

\subsection{Pengujian Rangkaian LED}

Pengujian rangkaian input ini dilakukan dengan cara mengukur tegangan pada pin dari Raspberry Pi yang terhubung pada LED pada saat LED dalam keadaan menyala dan pada saat LED dalam keadaan mati.

Tabel 7. Hasil Pengukuran LED

\begin{tabular}{|r|r|r|r|r|}
\hline \multirow{2}{*}{ Percobaan Ke } & \multicolumn{4}{|c|}{ LED } \\
\cline { 2 - 5 } & \multicolumn{2}{|c|}{ Menyala } & \multicolumn{2}{c|}{ Mati } \\
\cline { 2 - 5 } & Merah & Hijau & Merah & Hijau \\
\hline 1 & 3.12 & 3.2 & 0 & 0 \\
\hline 2 & 3.13 & 3.2 & 0 & 0 \\
\hline 3 & 3.12 & 3.19 & 0 & 0 \\
\hline 4 & 3.13 & 3.2 & 0 & 0 \\
\hline 5 & 3.12 & 3.2 & 0 & 0 \\
\hline 6 & 3.13 & 3.2 & 0 & 0 \\
\hline 7 & 3.12 & 3.2 & 0 & 0 \\
\hline 8 & 3.12 & 3.2 & 0 & 0 \\
\hline 9 & 3.12 & 3.2 & 0 & 0 \\
\hline 10 & 3.12 & 3.19 & 0 & 0 \\
\hline
\end{tabular}


Dari hasil pengukuran dapat diketahui bahwa tegangan yang dapat diberikan oleh Raspberry Pi sebagai tegangan HIGH adalah berkisar antara 3.12-3.2 Volt.

\subsection{Pengujian Perangkat Lunak}

Pengujian perangkat lunak dibagi kedalam beberapa bagian, yaitu pengujian perangkat lunak untuk rangkaian push-button, pengujian perangkat lunak untuk sensor infrared, pengujian kamera web dan pengujian perangkat lunak pada sistem database. Pengujian dilakukan langsung pada program Python 2.x pada Rasberry Pi.

\subsubsection{Pengujian Perangkat Lunak untuk Sensor I nfrared}

Pengujian ini dilakukan untuk mengetahui sensor infrared dapat terhubung dengan interface yang dibuat melalui port GPIO pada Raspberry Pi. Ada beberapa pengujian yang dilakukan yaitu pengujian dengan kedua sensor pada area parkir tidak terhalang oleh apapun, pengujian satu sensor terhalang dan yang satunya lagi tidak, dan pengujian kedua sensor terhalang. Untuk hasil pengujian dapat dilihat pada Tabel 8 untuk lantai 1 dan 8 untuk lantai 2.

Tabel 8. Hasil Pengujian Perangkat lunak Untuk Sensor Lantai 1

\begin{tabular}{|r|l|l|l|l|l|l|}
\hline \multirow{2}{*}{ No } & \multicolumn{2}{|c|}{ A1 } & \multirow{2}{*}{ Warna A1 } & \multicolumn{2}{|c|}{ A2 } & \multirow{2}{*}{ Warna A2 } \\
\cline { 2 - 3 } & Sensor 1 & Sensor 2 & & Sensor 1 & Sensor 2 & \\
\hline 1 & Terhalang & Terhalang & Merah & Terhalang & Terhalang & Merah \\
\hline 2 & Terhalang & Tidak Terhalang & Putih & Terhalang & Tidak Terhalang & Putih \\
\hline 3 & Tidak Terhalang & Terhalang & Putih & Tidak Terhalang & Terhalang & Putih \\
\hline 4 & Tidak Terhalang & Tidak Terhalang & Putih & Tidak Terhalang & Tidak Terhalang & Putih \\
\hline
\end{tabular}

Tabel 9. Hasil Pengujian Perangkat lunak Untuk Sensor Lantai 2

\begin{tabular}{|r|l|l|l|l|l|l|}
\hline \multirow{2}{*}{ No } & \multicolumn{2}{|c|}{ B1 } & \multirow{2}{*}{ Warna B1 } & \multicolumn{2}{|c|}{ B2 } & \multirow{2}{*}{ Warna B2 } \\
\cline { 2 - 3 } \cline { 5 - 6 } & Sensor 1 & Sensor 2 & & Sensor 1 & Sensor 2 & \\
\hline 1 & Terhalang & Terhalang & Merah & Terhalang & Terhalang & Merah \\
\hline 2 & Terhalang & Tidak Terhalang & Putih & Terhalang & Tidak Terhalang & Putih \\
\hline 3 & Tidak Terhalang & Terhalang & Putih & Tidak Terhalang & Terhalang & Putih \\
\hline 4 & Tidak Terhalang & Tidak Terhalang & Putih & Tidak Terhalang & Tidak Terhalang & Putih \\
\hline
\end{tabular}

Dari hasil pengujian diperoleh bahwa untuk dapat mengubah tampilan pada area parkir menjadi berwarna merah, sensor harus terhalang keduanya pada area parkir, jika hanya satu buah sensor saja yang terhalang atau keduanya tidak terhalang sama sekali tidak akan membuat tampilan pada area parkir berubah. Penggunaan 2 buah sensor pada 1 buah area parkir dimaksudkan agar saat 1 buah sensor terlewati oleh objek yang bukan kendaran melintas, tidak akan mempengaruhi sistem. Ini berarti perangkat lunak untuk bagian sensor telah berjalan sesuai dengan yang diharapkan.

\subsubsection{Pengujian Perangkat Lunak Untuk Push Button}

Pengujian ini dilakukan untuk mengetahui apa Push Button dapat terhubung dengan interface yang dibuat melalui port GPIO pada Raspberry Pi. Ada beberapa hasil yang akan dilihat dari pengujian ini yaitu warna dari area parkir setelah push button ditekan dan apakah push button mampu memberi perintah melalui Raspberry Piagar kamera web mengambil gambar. Gambar akan disimpan dengan format nama waktu diambilnya gambar dengan resolusi 640x480 piksel. Pengujian juga dimaksudkan untuk mengukur waktu yang dibutuhkan program untuk mengembalikan warna pada area parkir kembali menjadi putih. Untuk hasil pengujian dapat dilihat pada Tabel 10. 
Tabel 10. Hasil Pengujian Perangkat Lunak Terhadap Push Button

\begin{tabular}{|r|l|l|l|}
\hline No & Push Button & Warna Area Parkir Setelah ditekan & Status pengambilan Gambar \\
\hline 1 & A1 & Kuning & Berhasil \\
\hline 2 & A2 & Kuning & Berhasil \\
\hline 3 & B1 & Kuning & Berhasil \\
\hline 4 & B2 & Kuning & Berhasil \\
\hline
\end{tabular}

Dari tabel hasil pengujian push button berhasil membuat warna area parkir pada tampilan area parkir menjadi berwarna kuning dan sekitar dalam waktu 5 menit kembali menjadi berwarna putih. Keempat Push Button juga mampu membuat kamera web untuk mengambil gambar. Seperti yang diperlihatkan Gambar 10. Gambar 10 adalah gambar hasil dari tangkapan kamera web yang digunakan.

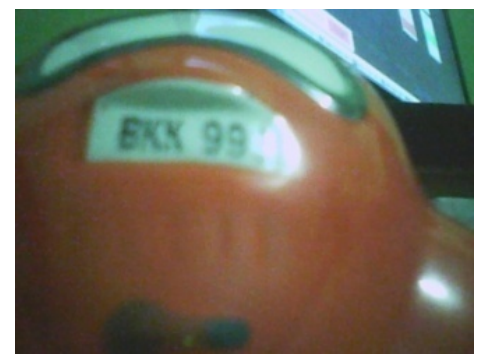

\section{Gambar 10. Hasil dari Tangkapan dengan Kamera Web}

\subsubsection{Pengujian Pengujian Perangkat Lunak Untuk LED}

Pengujian ini dilakukan untuk mengetahui apa lampu LED menyala sebagaimana semestinya, yaitu saat ada area yang masih kosong lampu LED putih akan menyala, dan pada saat seluruh area parkir terisi, lampu LED putih akan padam dan lampu LED merah akan menyala. Hasil dari pengujian dapat dilihat pada Gambar 11 dan Tabel 6.

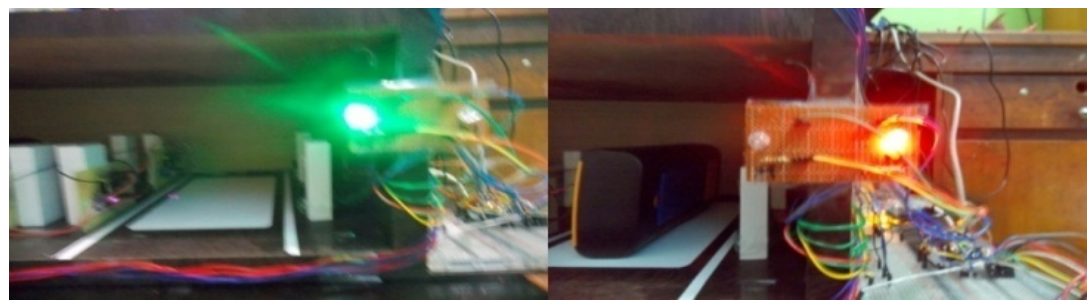

(a)

(b)

Gambar 11. Hasil dari Penguj ian Perangkat Lunak LED (a) LED Hijau (b) LED Merah

\subsubsection{Pengujian Database}

Untuk database pada sistem yang dirancang digunakan SQLite3. Saat push button ditekan pengendara parkir akan mendapat nomor tiket parkir dengan kode yang unik. Untuk perhitungan lama parkir dan biaya dihitung dengan sistem per-jam. Untuk 1 jam pertama biaya yang harus dibayarkan oleh pengendara adalah 2000 rupiah dan bertambah 1500 rupiah untuk setiap jamnya. Karena menggunakan sistem per-jam maka perhitungan lama parkir pun di bulatkan menjadi perjam. Adapun hasil dari pengujian database dapat dilihat pada Tabel 11. 
Tabel 11. Hasil Pengujian Database

\begin{tabular}{|l|l|l|l|l|l|l|l|}
\hline Id & Tiket Parkir & Tanggal Masuk & Jam Masuk & Tanggal Keluar & $\begin{array}{l}\text { Jam } \\
\text { Keluar }\end{array}$ & $\begin{array}{l}\text { Lama } \\
\text { Parkir }\end{array}$ & \begin{tabular}{l} 
Tarif \\
\hline 133
\end{tabular} \\
\hline & 20140620130038132 & $20-06-2014$ & $13: 00: 38$ & $20-06-2014$ & $17: 16: 29$ & 5 & 8000 \\
\hline 134 & 20140620130038133 & $20-06-2014$ & $13: 00: 38$ & $20-06-2014$ & $17: 21: 10$ & 5 & 8000 \\
\hline 135 & 20140620130042134 & $20-06-2014$ & $13: 00: 42$ & $21-06-2014$ & $02: 37: 34$ & 14 & 21500 \\
\hline 140 & 20140620130050139 & $20-06-2014$ & $13: 00: 50$ & $20-06-2014$ & $17: 24: 03$ & 5 & 8000 \\
\hline 141 & 20140620164605140 & $20-06-2014$ & $16: 46: 05$ & $20-06-2014$ & $17: 22: 05$ & 1 & 2000 \\
\hline 143 & 20140620165031142 & $20-06-2014$ & $16: 50: 31$ & $21-06-2014$ & $02: 37: 07$ & 10 & 15500 \\
\hline 149 & 20140620170035148 & $20-06-2014$ & $17: 00: 35$ & $20-06-2014$ & $17: 23: 02$ & 1 & 2000 \\
\hline 150 & 20140620170548149 & $20-06-2014$ & $17: 05: 48$ & $21-06-2014$ & $02: 36: 35$ & 10 & 15500 \\
\hline 164 & 20140620173736163 & $20-06-2014$ & $17: 37: 36$ & $21-06-2014$ & $02: 36: 04$ & 9 & 14000 \\
\hline 223 & 20140623193442222 & $23-06-2014$ & $19: 34: 42$ & $23-06-2014$ & $19: 36: 36$ & 1 & 2000 \\
\hline
\end{tabular}

Nomor tiket parkir merupakan kombinasi dari waktu ditekannya tombol pemesanan dengan nomor id dikurangi 1. Dapat dilihat pada tabel dengan id 141, 2014 merupakan tahun, 06 merupakan bulan, 20 merupakan tanggal, 16 merupakan jam, 46 dan 05 merupakan detik ditekannya tombol pemesanan, dan 140 merupakan nomor id yaitu 141 dikurangi 1 .

\subsection{Pengujian Fungsional Sistem}

\subsubsection{Kondisi Normal}

Lampu LED berwarna hijau yang berarti masih ada tempat parkir yang belum terisi. Pada layar tampak status semua blok parkir masih berwarna putih yang berarti seluruh area tempat parkir masih kosong belum terisi. Gambar 12 menunjukkan seluruh area blok parkir masih kosong.

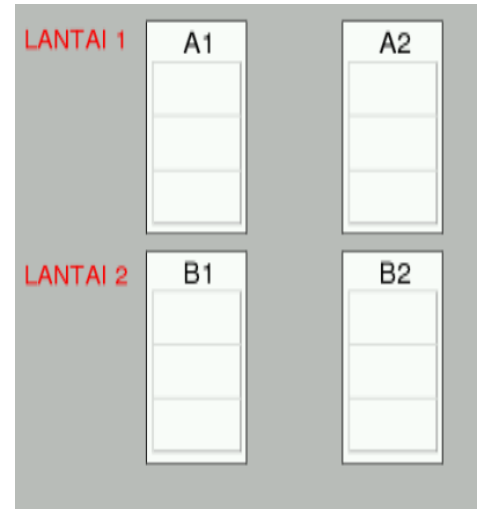

\section{Gambar 12. Kondisi Seluruh Blok Parkir Kosong}

Pada saat tombol pemilihan Al ditekan, blok area Al berubah warnanya menjadi kuning. Untuk kondisi blok Al setelah penekanan tombol dapat dilihat pada Gambar 13. 


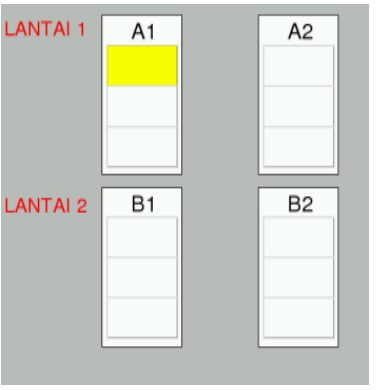

\section{Gambar 13. Kondisi Blok Al Setelah Tombol Al ditekan}

Kamera web akan mengambil gambar pada waktu yang bersamaan menyimpannya dengan format nama penyimpanan waktu diambilnya gambar yaitu tahun-bulantanggal|jam:menit:detik.jpg dengan resolusi 640×480 piksel. Selain itu pada tabel database akan tersimpan data waktu penekanan tombol yang kemudian akan dijadikan sebagai waktu masuknya kendaraan, tanggal penekanan tombol yang kemudian akan menjadi tanggal penekanan tombol dan nomor tiket parkir. Kemudian saat kendaraan sudah berada di area parkir yang telah disimpan, blok area parkir Al akan berubah warnanya menjadi warna merah seperti terlihat pada Gambar 14.



\section{Gambar 14. Kondisi Blok A1 Setelah Tombol A1 terisi kendaraan}

Bila kendaraan yang terparkir di blok area Al sudah selesai parkir dan keluar dari tempat parkir, area parkir Al akan kembali menjadi berwarna putih. Kemudian Operator memasukkan nomor tiket parkir yang dimiliki kendaraan tadi ke dalam kolom yang telah disediakan kemudian akan muncul informasi dari nomor tiket parkir tadi seperti jam masuk kendaraan, tanggal masuk kendaraan, serta tambahan informasi seperti lama parkir dan biaya yang harus dibayarkan pemilik kendaraan. Informasi jam keluar kendaraan, lama parkir kendaraan serta biaya yang harus dibayarkan secara otomatis akan terupdate pada tabel database yang digunakan.

\subsubsection{Kondisi Mobil Parkir Tidak Sesuai Area yang Dipesan}

Untuk pengujian dalam kondisi kendaraan tidak diparkirkan di tempat yang telah dipesan, Push button B1 ditekan, kemudian interface yang menunjukkan area B1 berubah menjadi berwarna kuning. Kemudian kendaraan diparkirkan di tempat lain yatu A2. Area A2 akan langsung berubah menjadi warna merah begitu sensor infrared terhalang kendaraan, sedangkan B1 tetap berwarna kuning. 5 menit kemudian, B1 kembali menjadi berwarna putih yang menunjukkan area parkir kosong. Pengujian dapat dilihat pada Gambar 15. 


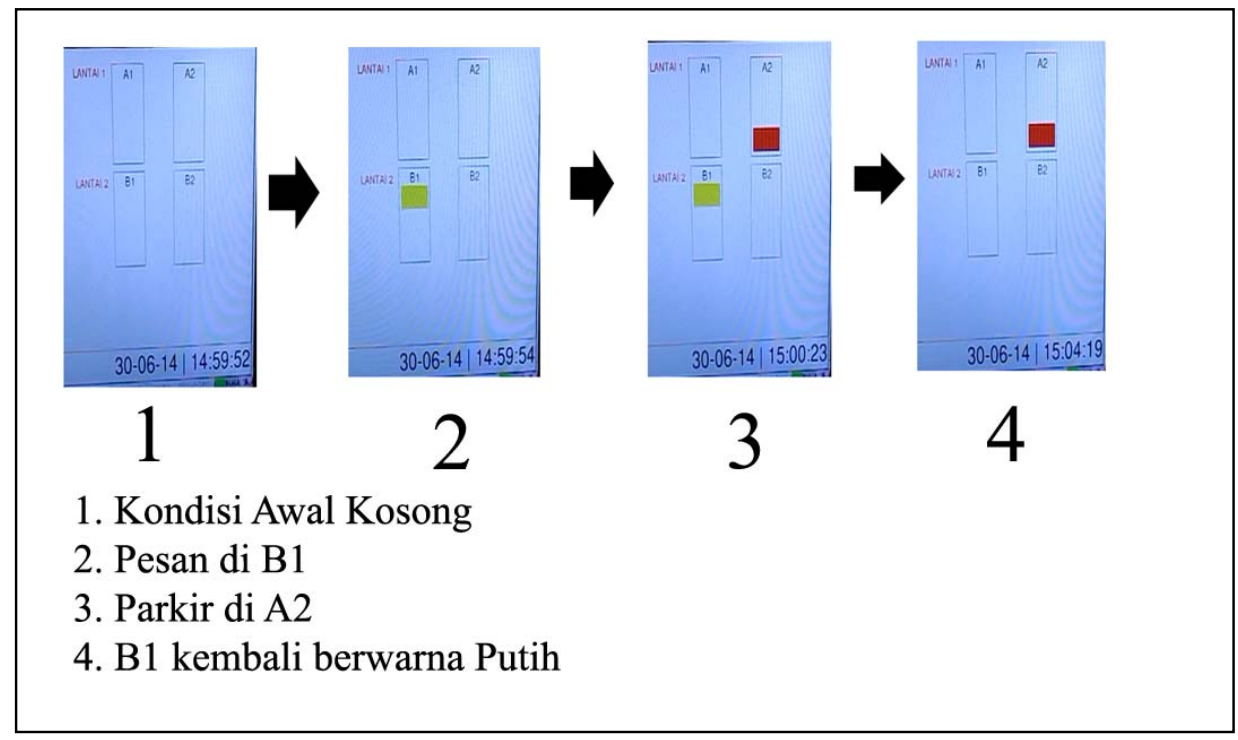

\section{Gambar 15. Pengujian Mobil Parkir Tidak Sesuai Area yang Dipesan}

\subsubsection{Kondisi Area Parkir Penuh}

Untuk pengujian tempat parkir dalam keadaan penuh, seluruh area parkir ditempati kendaraan, seperti terlihat pada Gambar 11 lampu LED berwarna Merah akan menyala dan lampu LED hijau akan mati. Pengujian dapat dilihat pada Gambar 16.

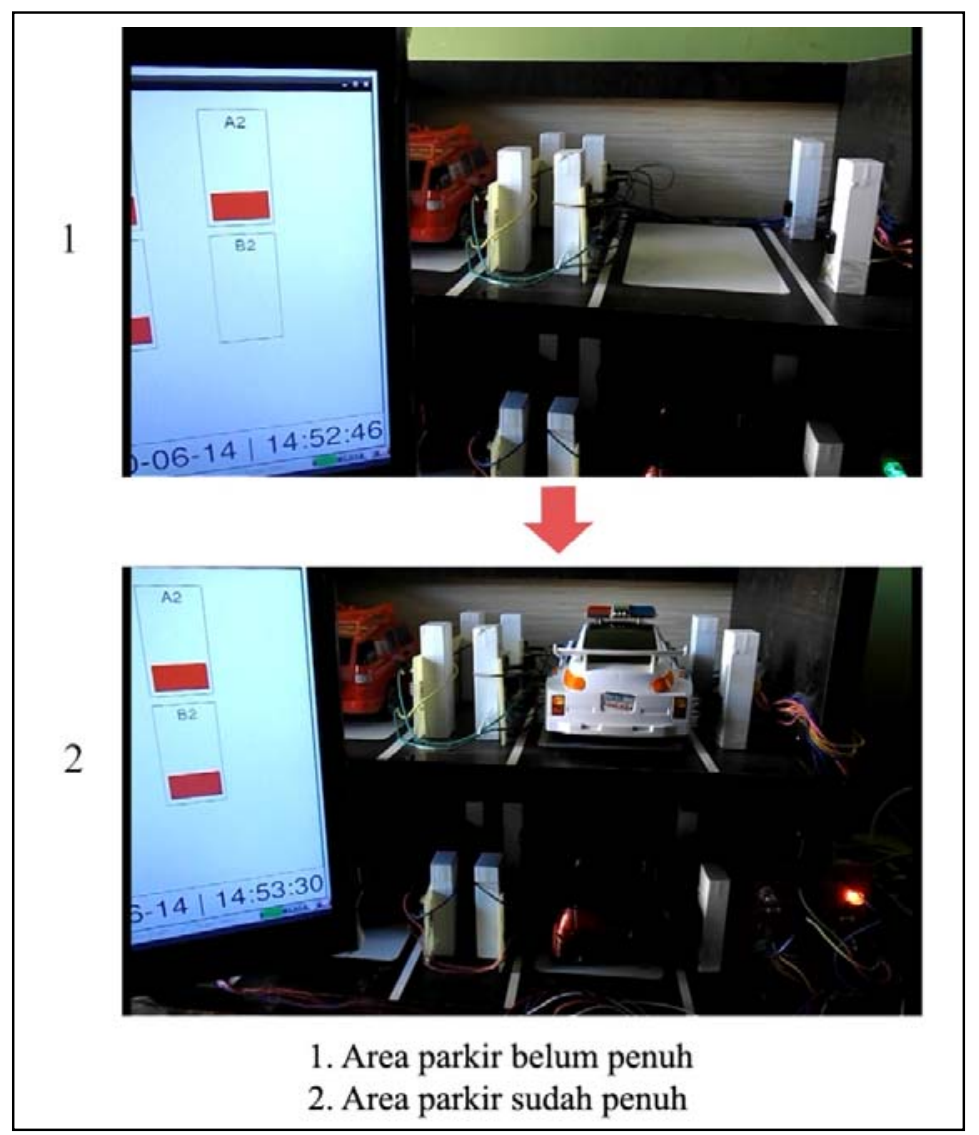

Gambar 16. Area Parkir Penuh 


\section{KESI MPULAN DAN SARAN}

\section{Kesimpulan}

Dari keseluruhan hasil perancangan, implementasi dan pengujian sistem dapat disimpulkan bahwa:

1. Cara pemesanan dan penempatan sensor tempat parkir telah dapat diaplikasikan pada miniatur sistem perparkiran 2 lantai dengan masing-masing lantai 2 blok parkir yang dirancang dan dapat berfungsi dengan baik.

2. Penggunaan sensor infrared dapat berfungsi mendeteksi ada tidaknya kendaraan pada setiap blok parkir, terlihat dari perubahan tegangan saat sensor parkir terhalang objek yaitu menghasilkan tegangan sebesar 3 Volt dan saat tidak terhalang objek menghasilkan tegangan sebesar 0 volt.

3. Berdasarkan pengujian Push Button untuk interface dan pengujian database, Push Button berhasil difungsikan untuk berbagai hal, mengubah warna objek pada interface, menjadi trigger bagi kamera web untuk mengambil gambar dan memberi inputan pada database yang kemudian digunakan sebagai nomor tiket yang berisikan informasi mengenai waktu kendaraan masuk. Tegangan yang dihasilkan saat Push Button ditekan adalah sebesar 3.25 Volt dan tegangan saat ridak ditekan adalah sebesar 0 Volt.

4. Raspberry mampu berperan sebagai pengendali sistem. Tidak hanya memproses inputan yang langsung diterima dari sensor yang terhubung pada GPIO Raspberry $P i$, tapi juga mampu menjalankan sistem database.

\section{Saran}

Beberapa saran yang dapat dikemukakan untuk pengembangan selanjutnya antara lain:

1. Sistem menggunakan 2 buah Raspberry Pi dimana salah satunya menggunakan layar sentuh di pintu masuk dan yang satunya digunakan oleh operator pada pintu keluar dan tehubung secara wireless.

2. Penggunaan kamera yang lebih baik dari segi kualitas agar dapat dilengkapi dengan pengolahan citra untuk mendeteksi nomor kendaraan.

3. Sistem dilengkapi dengan printer yang kompatibel dengan Raspberry Pi.

4. Sistem dilengkapi dengan palang pintu pada pintu masuk dan pintu keluar.

5. Diperhitungkan kondisi traffic pada saat akan parkir (teori antrian)

\section{DAFTAR RUJ UKAN}

Arnstein, S. R. (1969). A Ladder of Citizen Participation. Dalam R. T. Gates, \& F. Stout (Penyunt.), The City Reader (2nd ed.). New York: Routledge Press.

Borer, M. I. (2010). From Collective Memory to Collective Imagination: Time, Place, and Urban Redevelopment. Symbolic Interaction , 33 (1), 96-144.

Downey, A. B. (2012). Think Python. Sebastopol, California: O'REI LLY.

Lundh, F. (1999). An Introduction to Tkinter.

Mac Leod, D. (1992). Post-Modernism and Urban Planning. Dipetik June 25, 2010, dari http://www3.sympatico.ca/david.macleod/POMO.HTM

Matt Richardson \& Shawn Wallace. (2012). Getting Started qith Raspberry Pi. Sebastopol, California: O'REILLY. 
Nathan Oostendorp, Anthony Oliver, and Katherine Scott. (2012). Practical Computer Vision with SimpleCV. Sebastopol, California: O'REI LLY.

Owens, M. (2006). The Definitive Guide to SQLite. United States of America: Apress.

Poston, J. D., \& Bouvier, L. F. (2010). An Introduction to Demography. Cambridge: Cambridge University Press.

Stoica, R.-I. (2006 [2005]). Heterotopia Urbana: Some Conceptual Considerations of Urban Heritage. Forum UNESCO University and Heritage 10th International Seminar "Cultural Landscapes in the 21st Century". Newcastle-upon-Tyne.

Voskuil, R. P. (1996). Bandoeng: Beeld van Een Stad (Indonesian ed.). (S. M. Supardan, S. Sumardi, N. Darsono, \& I. I. Yousda, Penerj.) Bandung: Dept. Planologi and Jagaddhita.

Xi, Z. (2004). Comparison between American and Chinese Community Building. Dipetik May 10, 2007, dari COMM-ORG: The On-Line Conference on Community Organizing and Development: http://comm-org.wisc.edu/papers2004/zhangxi.htm.

Achdian, Asfin. (2012). Rancang Bangun Alat Monitoring Parkir Nirkabel berbasis Mikrokontroler ATMEGA8535. Bandung: Universitas Gunadarma.

Helmi, Asep Irfan. (2006). Perancangan dan Realisasi Model Sistem Perparkiran dengan Pemilihan Lantai Parkir berbasis Mikrokontroler dan PC pada Gedung Bertingkat. Bandung: Institut Teknologi Nasional. 